\title{
EFECTO QUIMIOPROTECTOR DEL EXTRACTO ALCALOIDEO DE Melocactus bellavistensis (CACTUS GLOBOSO) SOBRE EL CÁNCER DE COLON INDUCIDO CON 1,2-DIMETILHIDRAZINA EN RATAS
}

\author{
Karla Ríos-León ${ }^{1, a}$, Cesar Fuertes-Ruiton ${ }^{1, b}$, Jorge Arroyo², c, Julio Ruiz ${ }^{3, d}$
}

\begin{abstract}
RESUMEN
Objetivos. Determinar la toxicidad y el efecto quimioprotector del extracto alcaloideo de Melocactus bellavistensis (cactus globoso) sobre el cáncer de colon inducido en ratas con 1,2 dimetilhidrazina (DMH). Materiales y métodos. Se obtuvo el extracto alcaloideo de la parte carnosa de Melocactus bellavistensis, posteriormente, se realizó un ensayo de toxicidad aguda en 30 ratones de cepas Balb C57. Para evaluar su efecto quimioprotector se indujo el cáncer de colon en 45 ratas Holtzmann con DMH, según el siguiente diseño experimental: un grupo control con: polisorbato de sodio (PS) a $2 \mathrm{~mL} / \mathrm{kg}$ y cuatro grupos con DMH $20 \mathrm{mg} / \mathrm{kg}$ más $0,1,5$ y $10 \mathrm{mg} / \mathrm{kg}$ de extracto alcaloideo de Melocactus bellavistensis respectivamente. Resultados. Con una muestra de $5 \mathrm{~g}$ de extracto alcaloideo se determinó una DL50 mayor a 1000 $\mathrm{mg} / \mathrm{mL}$ en el ensayo de toxicidad aguda del extracto alcaloideo de Melocactus bellavistensis. Los resultados del efecto quimioprotector en los indicadores de estudio histopatológico revelaron que a las dosis de 5 y $10 \mathrm{mg} / \mathrm{kg}$ demostraron actividad antitumoral significativa en el cáncer de colon inducido por dimetilhidrazina en ratas con $100 \%$ de inhibición de neoplasia. Conclusiones. En condiciones experimentales, el extracto de alcaloides de Melocactus bellavistensis demostró tener efecto quimioprotector en cáncer de colon inducido por dimetilhidrazina en ratas.
\end{abstract}

Palabras clave: cáncer de colon, Melocactus bellavistensis, alcaloides, 1,2-dimetilhidrazina, toxicidad, efecto quimioprotector (Fuente: DeCS BIREME)

\section{CHEMOPROTECTIVE EFFECT OF THE ALKALOID EXTRACT OF Melocactus bellavistensis AGAINST COLON CANCER INDUCED IN RATS USING 1,2-DIMETHYLHYDRAZINE}

\begin{abstract}
Objectives. To determine the toxicity and chemoprotective effect of the alkaloid extract of Melocactus bellavistensis against colon cancer induced in rats using 1,2-dimethylhydrazine (DMH). Materials and methods. The alkaloid extract was obtained from the fleshy part of $M$. bellavistensis, and an acute toxicity test was then carried out on 30 mice of the Balb C57 strain. To assess its chemoprotective effect, colon cancer was induced in 45 Holtzman rats using DMH according to the following experimental design: one control group received $2 \mathrm{~mL} / \mathrm{kg}$ sodium polysorbate, and four groups received $20 \mathrm{mg} / \mathrm{kg}$ DMH plus $0,1,5$, or $10 \mathrm{mg} / \mathrm{kg} \mathrm{M}$. bellavistensis alkaloid extract. Results. With a sample of $5 \mathrm{~g}$ of alkaloid extract, an LD50 greater than $1000 \mathrm{mg} / \mathrm{mL}$ was determined in the acute toxicity test. Histological indicators revealed that the 5 and $10 \mathrm{mg} / \mathrm{kg}$ doses had significant anti-tumor activity with $100 \%$ neoplasia inhibition against DMHinduced colon cancer in rats. Conclusions. Under experimental conditions, the alkaloid extract of $M$. bellavistensis has a chemoprotective effect against $\mathrm{DMH}$-induced colon cancer in rats.
\end{abstract}

Key words: Colon cancer, Melocactus bellavistensis, alkaloid, 1.2-dimethylhydrazine, toxicity, chemopreventive effect. (Source: MeSH NLM).

\footnotetext{
Instituto de Ciencias Farmacéuticas y Recursos Naturales, Facultad de Farmacia y Bioquímica, Universidad Nacional Mayor de San Marcos. Lima, Perú. Instituto de Investigaciones Clínicas, Facultad de Medicina, Universidad Nacional Mayor de San Marcos. Lima, Perú.

Instituto de Investigación en Química Biológica, Microbiología y Biotecnología "Marco Antonio Garrido malo". Lima, Perú.

Químico farmacéutica; ${ }^{b}$ químico farmacéutico, magíster en Ciencias Farmacéuticas y Recursos Naturales; ${ }^{c}$ químico farmacéutico, doctor en Farmacia y Bioquímica; ${ }^{\mathrm{d}}$ químico farmacéutico, magíster en Microbiología.

Recibido: 07/07/2015 Aprobado: 21/12/2016 En línea: 23/03/2017
}

Citar como: Ríos-León K, Fuertes-Ruiton C, Arroyo J, Ruiz J. Efecto quimioprotector del extracto alcaloideo de Melocactus bellavistensis (cactus globoso) sobre el cáncer de colon inducido con 1,2-dimetilhidrazina en ratas. Rev Peru Med Exp Salud Publica. 2017;34(1):70-5. doi:10.17843/rpmesp.2017.341.2768 


\section{INTRODUCCIÓN}

En la actualidad, el cáncer es una de las principales causas de muerte a escala mundial. Se le atribuyen 8,2 millones de defunciones ocurridas en todo el mundo en 2012, y entre los principales tipos se encuentra el cáncer de colon, que es la cuarta causa principal de muerte por cáncer en el mundo y afecta en igual proporción a hombres y mujeres ${ }^{(1)}$. En el Perú, el cáncer colorrectal está entre los cinco de mayor prevalencia ${ }^{(2)}$. Las plantas tienen una larga historia en el tratamiento del cáncer, aunque muchas veces han sido observadas con cierto escepticismo por las características propias de la enfermedad ${ }^{(3,4)}$. De los productos de origen natural con actividad anticancerígena, los más conocidos son los alcaloides de la vinca (vinblastina y vincristina) aisladas de Catharanthus roseus (C. roseus), que fueron usadas en varias culturas para el tratamiento de la diabetes ${ }^{(4,5)}$. Es así que en nuestro país existen numerosas especies con propiedades medicinales que requieren ser estudiadas. Es ampliamente conocido que alcaloides de origen vegetal poseen actividad anticancerígena, como por ejemplo: los alcaloides de la vinca ${ }^{(5)}$, la campotecina, el placitaxol, la berberina y la capsaicina(6,7). La familia Cactaceae comprende más de 1500 especies, pero solo recientemente unas pocas de ellas han sido ensayadas por sus atributos quimiopreventivos y anticancerígenos, como Opuntia ficus ${ }^{\left({ }^{(8)}\right.}$. Por lo que es importante evaluar plantas nativas de la familia Cactaceae, para evaluar su poder citotóxico, en especial de sus alcaloides; así, Melocactus bellavistensis (cactus globoso) fue seleccionado para esta investigación.

Los modelos experimentales in vivo de cáncer de colon se han utilizado como bioensayos para el estudio de sustancias potencialmente protectoras frente a la carcinogénesis del colon ${ }^{(9)}$. Entre los modelos experimentales de cáncer de colon, los agentes que destacan para la inducción son la 1,2-dimetilhidrazina y el azoximetano (AOM). La dimetilhidrazina (DMH) es uno de los carcinógenos químicos más efectivos que induce cáncer del colon en el 80 a $100 \%$ de las ratas, entre 5 y 7 meses posteriores al inicio del tratamiento ${ }^{(10)}$.

La dimetilhidrazina se metaboliza en el hígado, dando como resultado intermediario al azoximetano; finalmente, este dará lugar a un agente carcinogenénico (ion diazonium),el cual, por alquilación de macromoléculas como el ADN, produce mutación ${ }^{(11)}$.El metabolismo de este carcinógeno genera sustancias citotóxicas para los colonocitos a las pocas horas de la inducción ${ }^{(12)}$. Esta etapa de iniciación se caracteriza por cambios en la homeostasis del epitelio intestinal que conducen al aumento de la proliferación. También es capaz de producir efectos tóxicos en diferentes lugares del tumor ${ }^{(13)}$. La flora intestinal, la dieta y el estado inmune de los ratones pueden interferir con el metabolismo de los compuestos carcinogénicos y, de ese modo, influir en su concentración local efectiva ${ }^{(14)}$.

Sobre la base de los estudios preliminares ${ }^{(15)}$ se evaluó el efecto del extracto alcaloideo de Melocactus bellavistensis, frente al cáncer de colon en ratas albinas (Holtzmann) con DMH.

\section{MATERIALES Y MÉTODOS}

La obtención del extracto alcaloideo, a partir de la parte carnosa de Melocactus bellavistensis, fue realizada por el método de maceración, usando metanol como solvente ${ }^{(16)}$. Previamente, en el macerado se determinó la presencia de alcaloides, para lo cual el extracto fue sometido a cromatografía de capa fina (CCF), usando una cromatoplaca de silicagel $60 \mathrm{~F}$ de $20 \times 20 \mathrm{~cm}$, como medio de solventes se usó cloroformo:metanol $(8: 0,8 \mathrm{v} / \mathrm{v})$ y como revelador el reactivo de Dragendorf(17).

El extracto fue concentrado en un evaporador rotatorio, luego tratado con amoniaco concentrado en un recipiente de color ámbar con tapa hermética por $48 \mathrm{~h}$. El extracto alcalino se trató con diclorometano, filtrado y lavado con agua destilada, en un embudo de decantación, la fase orgánica se acidificó con una solución de ácido clorhídrico diluido; la fase acuosa nuevamente se alcalinizó en una solución de amoniaco al $10 \%$, los alcaloides totales fueron extraídos con éter etílico. Finalmente, el solvente fue removido a presión reducida, precipitando el alcaloide que se dejó secar ${ }^{(18)}$.

Para la determinación de la toxicidad aguda (dosis letal 50:DL50) se utilizó treinta ratones machos cepa Balb C57 adquiridos en el Instituto Nacional de Salud, su peso promedio fue de $26 \pm 1 \mathrm{~g}$ al inicio del experimento; los ratones fueron mantenidos en un cuarto a temperatura controlada de $20 \pm 2{ }^{\circ} \mathrm{C}$, con un ciclo de luz/oscuridad de 12-12 h. La alimentación consistió en ratonina peletizada y agua a voluntad ${ }^{(20)}$.

Los ratones fueron distribuidos aleatoriamente en grupos de seis cada uno. Se les administró la sustancia mezclada con polisorbato de sodio al $3 \%$ por vía oral; al grupo 1 se le administró $10 \mathrm{~mL} / \mathrm{kg}$ de polisorbato de sodio al 3\%; al segundo, tercer, cuarto y quinto grupo, $10 \mathrm{mg} / \mathrm{kg}, 100 \mathrm{mg} / \mathrm{kg}, 500 \mathrm{mg} / \mathrm{kg}$ y $1000 \mathrm{mg} / \mathrm{kg}$ del extracto alcaloideo, respectivamente. Los animales fueron observados constantemente durante las primeras $24 \mathrm{~h}$, luego se continuó la observación diariamente durante 14 días, registrando cualquier síntoma tóxico que pudiera presentarse ${ }^{(21)}$.

Para la evaluación del efecto quimioprotector se indujo el cáncer de colon a 45 ratas Holtzmann con 1,2dimetilhidrazina (DMH) según Nalini et al., 2004(15), con modificaciones en pesos de ratas en el tiempo de administración de $\mathrm{DMH}$. Los animales utilizados para el estudio tenían dos meses y medio de edad con pesos $260 \pm 10 \mathrm{~g}$; divididas aleatoriamente según el siguiente diseño experimental: primer grupo: polisorbato de sodio a $2 \mathrm{~mL} / \mathrm{kg}$; segundo grupo: $\mathrm{DMH} 20 \mathrm{mg} / \mathrm{kg}$; tercer grupo, DMH más extracto alcaloideo de Melocactus bellavistensis a dosis de $1 \mathrm{mg} / \mathrm{kg}$, cuarto grupo, DMH más extracto alcaloideo de Melocactus bellavistensis a dosis de $5 \mathrm{mg} / \mathrm{kg}$; quinto grupo DMH más extracto alcaloideo de Melocactus bellavistensis a dosis de $10 \mathrm{mg} / \mathrm{kg}$. 
La dimetilhidrazina (DMH) fue preparada como una solución que contenía 400 mg de DMH disuelto en $100 \mathrm{~mL}$ de agua destilada estéril, $37 \mathrm{mg}$ de EDTA como agente estabilizador y mantenida a pH 6,5 con hidróxido de sodio. Se administró $20 \mathrm{mg} / \mathrm{kg}$ de peso corporal por vía subcutánea una vez a la semana, durante 18 semanas. Se administró por vía oral el extracto de alcaloides de Melocactus bellavistensis (cactus globoso) y el polisorbato de sodio al $3 \%$ por medio de una sonda metálica, iniciándose simultáneamente con la primera inoculación de DMH hasta las 18 semanas que duró el estudio ${ }^{(22) .}$

El último día del estudio, una hora después de la administración del extracto alcaloideo, las ratas fueron sacrificadas con pentobarbital $100 \mathrm{mg} / \mathrm{kg}$, y se les extrajo el colon para el análisis histopatológico, este fue lavado suavemente con solución salina para remover la sangre y los detritos adheridos al tejido; las zonas de masa tumoral fueron fijadas en solución de formol al 10\%, tamponado por 7 días; luego, se seleccionó partes de 3-5 um y fijadas en parafina, posteriormente fueron teñidas con hematoxilina y eosina. Los criterios de evaluación fueron en base a las observaciones microscópicas: neoplasia, displasia ${ }^{(22)}$. Para catalogar a la displasia y la neoplasia se tomó en cuenta lo siguiente:

Displasia: colon con picnosis, células de núcleo picnótico en la base de las glándulas de células basales, algunas agrupadas en forma de ramilletes, indicando polimorfonucleares con anisonucleosis (núcleos de distinto tamaño y dirección).

Neoplasia: colon con placas de Peyer con ganglios hipertrofiados, hipertrofia de placas de Peyer; conjunto de células redondas (macrófagos y células plasmáticas en el intersticio que hace relieve en luz a manera de penacho, crecimiento anormal.

El análisis estadístico para evaluar el efecto quimioprotector fue la prueba de normalidad de ShapiroWilk y, posteriormente, la prueba no paramétrica de Krustal Wallis con un $95 \%$ de nivel de confianza.

Para los experimentos con animales se siguió las recomendaciones éticas para manejo de animales de experimentación del Instituto Nacional de Salud del Perú (19).

\section{RESULTADOS}

Se obtuvo $5 \mathrm{~g}$ de extracto alcaloideo luego de procesar 4,7 kg de la parte carnosa del Melocactus bellavistensis, la presencia de alcaloides fue confirmada por el ensayo de cromatografía fina (resultados no mostrados).

El estudio de toxicidad aguda mostró que la administración por vía oral del extracto alcaloideo de Melocactus bellavistensis, a las dosis ensayadas, no indujo cambios ni muertes a las 6 y 24 h de observación, llegando a permanecer los ratones en aparente buen estado general hasta los quince días de observación, esto es una indicación que en las dosis ensayadas los alcaloides presentes en el extracto de Melocactus bellavistensis no inducen la muerte, y que la dosis letal 50 es mayor a los $1000 \mathrm{mg} / \mathrm{kg}$ cuando se administra por vía oral a estos animales.

Respecto a los diversos parámetros evaluados en el modelo experimental del efecto quimioprotector, en la Tabla 1 se resume el porcentaje de las observaciones histopatológicas del colon de ratas inducidas con cáncer de colon por $\mathrm{DMH}$ y que recibieron el extracto alcaloideo de Melocactus bellavistensis, se puede destacar que en los grupos tratados con el extracto alcaloideo no se observó neoplasia y se aceptó la hipótesis de que existe diferencia significativa entre los tipos de tratamiento y la fase de desarrollo de cáncer (normal, displasia y neoplasia), luego de aplicar, en primer lugar, la prueba de normalidad de Shapiro-Wilk, que reveló que se debería trabajar con pruebas no paramétricas como la de Krustal Wallis, al aplicar esta última prueba con un nivel de confianza de $95 \%$ se encontró un $p<0,05$ en todos los casos. Es así que a las concentraciones de 10,5 y $1 \mathrm{mg} / \mathrm{kg}$ no se observa neoplasia y hay porcentaje de displasia de 33,3\%, 22,2\% y 33,3\%, respectivamente. De esta manera, demostramos que a las concentraciones trabajadas hay una diferencia significativa respecto al grupo de animales tratados con el tóxico, donde se desarrolló neoplasia y displasia en un 66,7 y $33,3 \%$, respectivamente.

En la Figura 1 tenemos las observaciones histopatológicas del colon de ratas a quienes se les

Tabla 1. Observaciones histopatológicas del colon de ratas, inducidas con cáncer de colon por dimetilhidrazina $(\mathrm{DMH})$ y que recibieron el extracto alcaloideo de Melocactus bellavistensis (porcentaje de frecuencia)

\begin{tabular}{lcc}
\hline $\begin{array}{l}\text { Observación } \\
\text { histopatológica }\end{array}$ & Tratamiento & $\begin{array}{c}\text { Frecuencia } \\
\text { (\%) }\end{array}$ \\
\hline Normal & Solución PS & 100 \\
& DMH & 0 \\
& DMH + extracto $1 \mathrm{mg} / \mathrm{kg}$ & 33,3 \\
& $\mathrm{DMH}+$ extracto $5 \mathrm{mg} / \mathrm{kg}$ & 77,8 \\
& $\mathrm{DMH}+$ extracto $10 \mathrm{mg} / \mathrm{kg}$ & 66,7 \\
\hline Displasia & Solución PS & 0 \\
& DMH & 33,3 \\
& $\mathrm{DMH}+$ extracto $1 \mathrm{mg} / \mathrm{kg}$ & 66,7 \\
& $\mathrm{DMH}+$ extracto $5 \mathrm{mg} / \mathrm{kg}$ & 22,2 \\
& $\mathrm{DMH}+$ extracto $10 \mathrm{mg} / \mathrm{kg}$ & 33,3 \\
\hline \multirow{5}{*}{ Neoplasia } & Solución PS & 0 \\
& $\mathrm{DMH}$ & 66,7 \\
& $\mathrm{DMH}+$ extracto $1 \mathrm{mg} / \mathrm{kg}$ & 0 \\
& $\mathrm{DMH}+$ extracto $5 \mathrm{mg} / \mathrm{kg}$ & 0 \\
& $\mathrm{DMH}+$ extracto $10 \mathrm{mg} / \mathrm{kg}$ & 0 \\
\hline
\end{tabular}

PS: polisorbato de sodio al $3 \%$

La evaluación estadística se realizó mediante la prueba de KruskalWallis, para determinar la distribución en cada grupo de etapa de cáncer respecto a las categorías de tratamiento; nivel de significancia de 0,05. Normal $(p=0,01)$, displasia $(p=0,049)$, neoplasia $(p=0,01)$ 


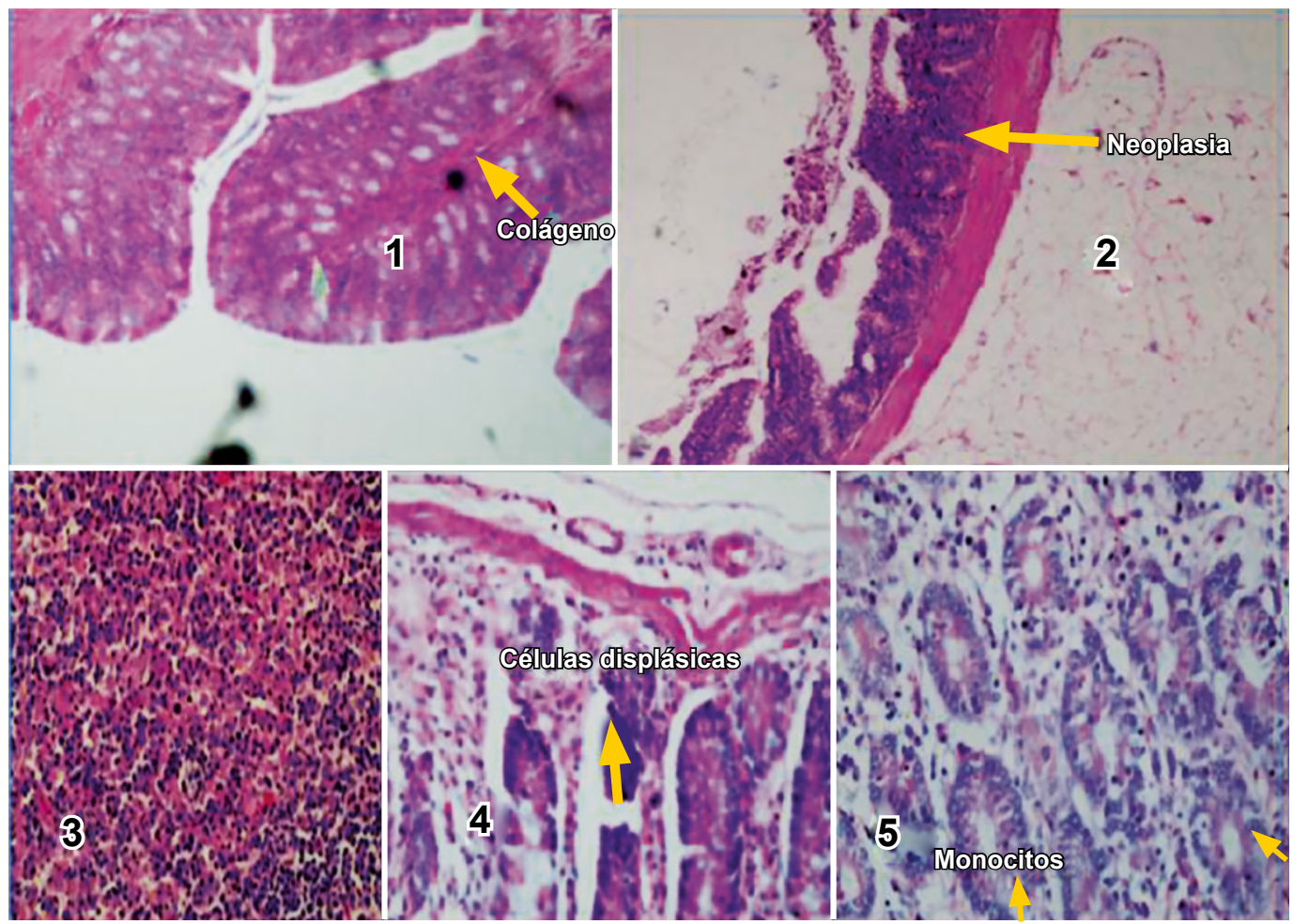

Figura 1. Observaciones histopatológicas del colon de ratas a quienes se les indujo el cáncer de colon por dimetilhidrazina (DMH) y que recibieron los alcaloides de Melocactus bellavistensis (cactus globoso). 1. Normal (SSF) $2 \mathrm{~mL} / \mathrm{kg}$. 2. Dimetilhidrazina $20 \mathrm{mg} / \mathrm{kg}$. 3. DMH + extracto alcaloideo $1 \mathrm{mg} / \mathrm{kg}$. $4 . \mathrm{DMH}+$ extracto alcaloideo $5 \mathrm{mg} / \mathrm{kg}$. 5.DMH + extracto alcaloideo $10 \mathrm{mg} / \mathrm{kg}$

indujo el cáncer de colon por dimetilhidrazina (DMH) y que recibieron el extracto alcaloideo de Melocactus bellavistensis (cactus globoso).

\section{DISCUSIÓN}

En la parte carnosa de Melocactus bellavistensis se encontraron alcaloides, hallazgo que concuerda con el trabajo de Acosta et al. ${ }^{(23) ;}$; Britt\& Rose ${ }^{(24)}$ también reportan la presencia del alcaloide cactina en Melocactus communis, lo cual confirma que las especies del género Melocactus presentan este importante metabolito secundario.

Hasta el momento no se han realizado estudios sobre la citotoxicidad ni actividad farmacológica del extracto alcaloideo de Melocactus bellavistensis (cactus globoso), razón por la cual no podemos hacer comparaciones de resultados para dicha especie. Los resultados obtenidos en este trabajo se compararán con estudios similares realizados en otras especies y géneros de la familia Cactaceae.

En la evaluación histopatológica del tejido de colon de las ratas tratadas con el extracto alcaloideo de Melocactus bellavistensis (cactus globoso), se observó una menor cantidad de células de tejido colónico con morfología alterada; así, a medida que aumentaron las concentraciones del extracto alcaloideo de $M$. bellavistensis, disminuye considerablemente el daño celular y la formación de tumores. Un posible mecanismo sería que la administración del extracto alcaloideo de $M$. bellavistensis aumentaría la capacidad del organismo de destruir las células alteradas y que esta se encuentra en relación directa a la concentración. En un estudio con un modelo similar, Justil et al. ${ }^{(25)}$ demostraron el efecto antitumoral in vivo del extracto etanólico de las hojas de Baccharis genistelloides, encontrando que la dosis de $500 \mathrm{mg} / \mathrm{kg}$ de este extracto presenta una mayor actividad dosis dependiente, al igual que los resultados obtenidos en nuestro estudio, ya que si la comparamos con la dosis de $10 \mathrm{mg} / \mathrm{kg}$ del extracto de alcaloides de $M$. bellavistensis solo mostró un ligero aumento de glándulas colónicas con infiltración discreta, además de la presencia de monocitos; similares resultados se observaron con la dosis intermedia de $250 \mathrm{mg} / \mathrm{kg}$, dosis equivalente a la de $5 \mathrm{mg} / \mathrm{kg}$ de nuestro estudio, donde no hubo compromiso fuera de la membrana basal y con la dosis menor de $100 \mathrm{mg} / \mathrm{kg}$, que equivaldría a la de $1 \mathrm{mg} / \mathrm{kg}$, se observó adenocarcinoma glandular; así también, en cuanto a los grupos con dimetilhidrazina, 
en donde en ambos estudios se observó neoplasia, con tumoraciones colónicas. Este es el primer reporte de una actividad biológica de la especie Melocactus bellavistensis, e inclusive tampoco hay reportes científicos de actividades biológicas en otras especies del género Melocactus. Los curanderos la usan como sustituto del cacto columnar san pedro, como planta visionaria. También, en pequeñas dosis, se come el parénquima y los frutos para aplacar la sed y el hambre. En muchos lugares de ceja de selva se cultiva en macetas como planta ornamental; similares usos se le atribuyen a la especie Melocactus bahiensis (Britton \& Rose) Luetzelb(26).

La familia Cactaceae comprende más de 1500 especies, pero hasta hace poco solo algunas de ellas han sido probadas por sus atributos quimiopreventivos y contra el cáncer. Las plantas de la familia de las cactáceas son principalmente desérticas y semidesérticas, las cuales, debido a condiciones de estrés ambientales adversas (escasez de agua, radiación fuerte, las diferencias de temperatura, y el pobre suelo) pueden haber desarrollado sistemas de defensa altamente eficaces, lo que les permite hacer frente con éxito el medioambiente. Estos sistemas de defensa están hechos de fitoquímicos, tales como alcaloides, flavonoides, terpenos, y taninos, que ya demostraron notable bioactividad contra enfermedades humanas tales como el cáncer y la diabetes ${ }^{(8)}$. Es así que, a pesar del limitado tamaño de muestra de ratas en el diseño del ensayo de la actividad quimioprotectora, los metabolitos secundarios, y en particular los alcaloides de la cactácea Melocactus bellavistensis, podrían explicar dicha actividad.

No existen reportes sobre la actividad de alcaloides con actividad anticancerígena en la familia Cactaceae, pero sí se reporta la acción antineoplásica de betaina aislada de Opuntia ficus-indica, fitol y a-tocoferol aisladas de Pleskiableo (Kunth) DC, peniocerol aislada de Mirtillocactus geometricus, ácido betulínico aislado de Stenocereus stellatus y polisacáridos de cactáceas no identificadas ${ }^{(8)}$; aunque ninguna de ellas ensayada contra modelos de cáncer de colon ya sea in vivo o in vitro.

No hay estudios contra modelos de cáncer de colon in vivo en la familia cactaceae, excepto el reportado en la presente investigación; sin embargo, en el estudio realizado por Chavez-Santoscoy et al. demostraron que el jugo de la Opuntia violaceae tenía efecto anticancerígeno contra la línea celular de cáncer de colon Caco-2 ${ }^{(27)}$. Por otro lado, en la familia Cactaceae se han reportado varios estudios in vivo de los efectos anticancerígenos, entre ellos el del extracto acuoso de la penca de Opuntia ficusindica, que revierte el efecto del cáncer hepático inducido por aflatoxina B1 en ratones machos BALB/c (28); el del extracto acuoso de la pera de Opuntia ficus-indica, el cual suprime el crecimiento de tumores en ratones hembra
BALC/c xenoinjertado con células SKOV3 relacionadas con cáncer cervical ${ }^{29)}$. En otro estudio se reporta que el polvo del fruto del cactus de Opuntia humifusa disminuye el número de papilomas y la hiperplasia epidermal en ratones hembra BALC/c tratadas con 7, 12-Dimetilbenz[a] antraceno ${ }^{(30)}$. Todo esto avala el potencial de la familia Cactaceae como fuente de anticancerígenos, entre ellos al Melocactus bellavistensis.

Los alcaloides del Melocactus bellavistensis serían los responsables de la acción quimioprotectora, existen evidencias en otros estudios que los alcaloides tienen esta acción sobre el cáncer de colon, entre ellos tenemos a la chabamida $G$ y la sintenpiridona (amida alcaloides del género Piper) que mostraron potente actividad contra líneas celulares de adenocarcinoma de colon (COLO-205 y HT-20) ${ }^{(31)}$, un derivado del alcaloide fenantroindolizidina, YPC-10157, que tuvo un fuerte efecto antitumoral en modelos xenoinjertados de cáncer de colon y leucemia (32); por otro lado, la berberina, alcaloide cuaternario isoquinolina, presente en numerosas plantas medicinales, fue probada por su potencial quimioprotector en células de cáncer de colon (SW480) e inhibió la proliferación de estas de una manera dosis- y tiempo-dependiente ${ }^{(33)}$. Finalmente, el posible mecanismo de acción de los alcaloides contra el cáncer de colon están relacionados a la detención del ciclo celular, inducción de apoptosis e inhibición de la inflamación, que fueron demostrados experimentalmente con el alcaloide berberina ${ }^{(33,34)}$, por lo que es posible que alguno de estos mecanismos sea el responsable de la acción quimioprotectora de los alcaloides del Melocactus bellavistensis.

En conclusión, la dosis letal 50 por vía oral del extracto alcaloideo de Melocactus bellavistensis (cactus globoso) en ratones, a dosis única, estaría por encima de 1000 $\mathrm{mg} / \mathrm{kg}$, y en condiciones experimentales presentó efecto quimioprotector sobre el cáncer de colon inducido en ratas por 1,2-dimetilhidrazina, con reducción de los niveles de displasia e inhibición de neoplasia.

Agradecimientos: los autores agradecen al licenciado en Biología José Ricardo Campos de La Cruz por su apoyo en la recolección e identificación botánica de la especie utilizada en la investigación.

Contribuciones de autoría: JAA, CFR y KRL participaron en la concepción del artículo, recolección de la información, interpretación de los resultados, elaboración de la discusión. $J R Q Y K R L$ participaron en la redacción del artículo y su revisión crítica. JAA, CFR, KRL y JRQ participaron en la aprobación de la versión final.

Fuentes de financiamiento: Consejo Superior de Investigación de la Universidad Nacional Mayor de San Marcos.

Conflictos de interés: los autores declaran no tener conflictos de interés en la en la publicación de este artículo. 


\section{REFERENCIAS BIBLIOGRÁFICAS}

1. Organización Mundial de la Salud. Cáncer. Nota descriptiva [Internet]. Ginebra: OMS; 2015 [citado el 11 de mayo del 2015]. Disponible en: http:// www.who.int/mediacentre/factsheets/ fs297/es/

2. Organización Mundial de la Salud. Perfiles oncológicos de los países, Perú [Internet]. Ginebra: OMS; 2014 [citado el 09 de mayo de 2015]. Disponible en: http://www.who.int/cancer/countryprofiles/per_es.pdf?ua $=1$

3. Khazir J, Riley DL, Pilcher LA, DeMaayer P, Mir BA. Anticancer agents from diverse natural sources. Nat Prod Commun. 2014;9(11):1655-69.

4. Sultana S, Asif HM, Nazar HM, Akhtar N, Rehman JU, Rehman RU. Medicinal plants combating against cancer--a green anticancer approach. Asian Pac J Cancer Prev. 2014;15(11):4385-94.

5. Orlikova B, Legrand N, Panning J, Dicato M, Diederich M. Anti-inflammatory and anticancer drugs from nature. Cancer Treat Res. 2014;159:123-43.doi: 10.1007/978-3-642-38007-5_8.

6. Hosseini A, Ghorbani A. Cancer therapy with phytochemicals: evidence from clinical studies. Avicenna J Phytomed. 2015;5(2):84-97.

7. Chen ZF, Liu YC, Huang KB, Liang H. Alkaloid-metal based anticancer agents..Curr Top Med Chem. 2013; 13(17):2104-15. doi: $10.2174 / 15680266113139990146$.

8. Harlev E, Nevo E, Solowey E, Bishayee A. Cancer preventive and curative attributes of plants of the Cactaceae family: a review. Planta Med. 2013;79(9):713-22. doi: $10.1055 / \mathrm{s}-0032-1328632$.

9. Corpet DE, Pierre F. Point: From animal models to prevention of colon cancer. Systematic review of chemoprevention in min mice and choice of the model system. Cancer Epidemiol Biomarkers Prev. 2003;12(5):391-400.

10. Newberne PM, Rogers AE. Animal model of human disease. Adenocarcinoma of the colon. Am J Pathol. 1973;72(3):541-4.

11. Sohn OS, Fiala ES, Requeijo SP, Weisburger JH, Gonzalez FJ. Differential effects of CYP2E1 status on the metabolic activation of the colon carcinogens azoxymethane and methylazoxymethanol. Cancer Res. 2001;61(23):8435-40.

12. Reddy BS. Studies with the azoxymethane-rat preclinical model for assessing colon tumor development and chemoprevention. Environ Mol Mutagen. 2004;44(1):26-35. doi: 10.1002/em.20026.

13. Bobek $\mathrm{P}$, Galbavý $S$, Mariássyová $\mathrm{M}$. The effect of red beet (Beta vulgaris var. rubra) fiber on alimentary hypercholesterolemia and chemically induced colon carcinogenesis in rats. Nahrung. 2000;44(3):184-7.
14. Corpet DE, Pierre F. How good are rodent models of carcinogenesis in predicting efficacy in humans? A systematic review and meta-analysis of colon chemoprevention in rats, mice and men. Eur J Cancer. 2005;41(13):191122. doi: http://dx.doi.org/10.1016/j. ejca.2005.06.006.

15. Nalini N, Manju V, Menon VP. Effect of coconut cake on the bacterial enzyme activity in 1,2-dimethyl hydrazine induced colon cancer.ClinChimActa. 2004;342(1-2):203-10. doi:10.1016/j. cccn.2004.01.001.

16. Acosta-León, K. Identificación de los alcaloides de Stenomesson aurantiacum (Kunth) Herb. Tesis de magister. Universitat de Barcelona. Barcelona, España. 2013.

17. Wagner H, Bladt S. Plant Drug Analysis: A Thin Layer Chromatography Atlas. $2^{\text {nd }}$ ed. Berlin: Springer Science \& Business Media; 1996.

18. Vinueza AG. Tamizaje fitoquímico e identificación de alcaloides de Phaedranassa schizantha Baker. Tesis para obtener el grado de Bioquímico Farmacéutico. Facultad de Ciencias: Escuela Superior Politécnica de Chimborazo, Escuela Superior Politécnica de Chimborazo. Riobamba, Ecuador. 2014.

19. Fuentes F, Mendoza R, Rosales A, Cisneros R. Guía de manejo y cuidado de animales de laboratorio: Ratón. Lima: INS; 2008. p. 19-21.

20. Arroyo J, Bonilla P, Moreno-Exebio L, Ronceros G, Tomas G, Huamán J, et al. Efecto gastroprotector y antisecretor de un fitofármaco de hojas de matico (Piperaduncum). Rev Peru Med Exp Salud Publica. 2013;30(4):608-15.

21. Arroyo J, Herrera $\mathrm{O}$, Chávez R, Ventura E, Buendía J, Pacheco J, et al. Efecto antitumoral in vitro del aceite esencial de Piperaduncum L. (matico) y su toxicidad oral en ratones. An Fac med. 2014;75(1):13-8.

22. Arroyo J, Bonilla $\mathrm{P}$, Oré $\mathrm{R}$, Ráez E, Marín M, Valencia J, et al. Estudio morfohistológico y efecto quimioprotector de las hojas de Bidens pilosa L. sobre el cáncer de colon inducido en ratas. An Fac med. 2008;69(2):77-83.

23. Acosta K, Lara H, Piaun K, Cazorla J. Estudio fitoquímico de la especie Melocactus Bellavistensis encontrada en el valle de Catamayo, provincia de LojaEcuador. Riobamba: Escuela Superior Politécnica de Chimborazo; 2015.

24. Rosadio Vega JR. Farmacopea Guajira: cosmovisión y usos de las plantas medicinales por los Wayuu. $2^{\text {da }}$ ed. Riohacha: Universidad de La Guajira; 2009.

25. Justil H, Arroyo J, Valencia J. Extracto etanólico de Baccharisgenistelloides (carqueja) sobre el cáncer de colon inducido con 1,2-dimetilhidrazina en ratas. An Fac med. 2010;71(2):88-96.

26. Lucena CM, Lucena RF, Costa GM, Carvalho TK, Costa GG, Alves RR, et al. Use and knowledge of Cactaceae in Northeastern Brazil. J Ethnobiol Ethnomed. 10.1186/1746-4269-9-62.

27. Chavez-Santoscoy RA, GutierrezUribe JA, Serna-Saldivar SO. Phenolic composition, antioxidant capacity and in vitro cancer cell cytotoxicity of nine prickly pear (Opuntia spp.) juices. Plant Foods Hum Nutr. 2009; 64(2):146-52. doi: 10.1007/s11130-009-0117-0.

28. Brahmi D, Bouaziz C, Ayed Y, Ben Mansour $\mathrm{H}$, Zourgui L, Bacha $\mathrm{H}$. Chemopreventive effect of cactus Opuntia ficus indica on oxidative stress and genotoxicity of aflatoxin B1. Nutr Metab (Lond). 2011;8:73. doi: 10.1186/1743-7075-8-73.

29. Zou DM, Brewer M, Garcia F, Feugang JM, Wang J, Zang R, et al. Cactus pear: a natural product in cancer chemoprevention. Nutr J. 2005;4:25. doi: $10.1186 / 1475-2891-4$ 25.

30. Lee JA, Jung BG, Lee BJ. Inhibitory effects of Opuntia humifusa on 7,12-dimethyl-benz[a] anthracene and 12-O-tetradecanoylphobol13-acetate induced two-stage skin carcinogenesis. Asian Pac J Cancer Prev. 2012;13(9):4655-60.

31. Wang YH, Morris-Natschke SL, Yang J, Niu HM, Long CL, Lee KH. Anticancer principles from medicinal piper (hú jiāo) plants. J Tradit Complement Med. 2014;4(1):8-16.doi: $\quad$ 10.4103/22254110.124811.

32. Ueno S, Yamazaki R, Ikeda T, Yaegashi T, Matsuzaki T. Antitumor effect of a novel phenanthroindolizidine alkaloid derivative through inhibition of protein synthesis. Anticancer Res. 2014;34(7):3391-7.

33. Chidambara Murthy KN, Jayaprakasha GK, Patil BS. The natural alkaloid berberine targets multiple pathways to induce cell death in cultured human coloncancer cells. Eur J Pharmacol. 2012;688(1-3):14-21.doi: $\quad$ 10.1016/j. ejphar.2012.05.004.

34. Guamán Ortiz LM, Tillhon $\mathrm{M}$, Parks M, Dutto I, Prosperi E, Savio $\mathrm{M}$, et al. Multiple effects of berberine derivatives on colon cancer cells. Biomed Res Int. 2014;2014:924585. doi: $10.1155 / 2014 / 924585$.

Correspondencia: Karla Giovanna Rios León Dirección: calle B Mz B lote 35. lera etapa. Urb. Santo Domingo-Carabayllo

Teléfono: 3222706

Correo electrónico:karlariosleon@hotmail.es 